\title{
A Determination of the Serum Ascitic Fluid Albumin Concentration Gradient in Children with Chronic Liver Disease and Nephrotic Syndrome
}

\author{
Md. Zakaria ${ }^{1, ~ *, ~ A S M ~ B a z l u l ~ K a r i m ², ~ M o h a m m a d ~ M o n i r ~ H o s s a i n ~}{ }^{3}$, \\ Md. Wahiduzzaman Mazumder ${ }^{2}$, Md. Mostafa Zaman ${ }^{4}$, Nadira Parvin ${ }^{5}$ \\ ${ }^{1}$ Depterment of Paediatrics, Sunamgong Sadar Hospital, Sunamgong, Sylhet, Bangladesh \\ ${ }^{2}$ Depterment of Paediatric Gastroenterology, Bangabandhu Sheikh Mujib Medical University, Dhaka, Bangladesh \\ ${ }^{3}$ Depterment of Paediatric Neurology, Bangabandhu Sheik Mujib Medical University (OSD), Dhaka, Bangladesh \\ ${ }^{4}$ Depterment of Paediatrics, M Abdur Rahim Medical College (MARMC), Dinajpur, Bangladesh \\ ${ }^{5}$ Depterment of Pharmacology and Therapeutics, TMSS Medical College, Bogura, Bangladesh \\ Email address: \\ drzakariabbaria@gmail.com (Md. Zakaria) \\ ${ }^{*}$ Corresponding author
}

\section{To cite this article:}

Md. Zakaria, ASM Bazlul Karim, Mohammad Monir Hossain, Md. Wahiduzzaman Mazumder, Md. Mostafa Zaman, Nadira Parvin. A Determination of the Serum Ascitic Fluid Albumin Concentration Gradient in Children with Chronic Liver Disease and Nephrotic Syndrome. American Journal of Pediatrics. Vol. 6, No. 4, 2020, pp. 386-391. doi: 10.11648/j.ajp.20200604.11

Received: February 5, 2020; Accepted: April 23, 2020; Published: September 30, 2020

\begin{abstract}
This prospective cross sectional study was carried out in the Department of Paediatrics, Bangabandhu Sheikh Mujib Medical University, Dhaka Medical College Hospital and Dhaka Shishu Hospital, Dhaka for a period of one year and six months starting from July 2012 to December 2013. The main objective of the study was to determine the serum ascitic fluid albumin concentration gradient in children with chronic liver disease and nephrotic syndrome. A total of 55 children were studied. Among them, 31 children with chronic liver disease with ascites were designated as Group I and rest 24 nephrotic syndrome children with ascites were designated as group II. The mean age of the children was 8.3 \pm 3.6 years ranging from 1.015.0 years. The mean age of the male patient was $8.0 \pm 3.6$ years and that of female patients was $9.3 \pm 3.5$ years. No statistically significant mean age difference was found between male and female patients $(p>0.05)$, although female patients had a bit higher mean age than male patients. The mean age of the group I patients was 9.2 \pm 3.7 years ranging from 1.0-14.0 years and group II patients was $7.2 \pm 3.2$ ranging from 2.0 to 15.0 years and the mean age difference between two groups patients was statistically significant $(\mathrm{p}<0.05)$ indicated that patients with chronic liver disease had higher age than patients with nephrotic syndrome. Chronic liver diseases patients where liver biopsy could not be performed to ascertain the exact nature of the disease were labeled as unclassified chronic liver disease. The aetiology of chronic liver diseases of the group I patients. Out of 31 patients, highest percentage of patients were of unknown etiology 17 (54.9\%) followed by hepatitis B virus $7(22.6 \%)$ and Wilson's disease 5 (16.1\%). It was evident that $24(77.4 \%)$ had serum bilirubin $>1.2 \mathrm{mg} / \mathrm{dl}$, serum ALT $>40$ IU/L was 25 (80.6\%), prothrombin time more than 3 second than control 23 (74.2\%) and serum albumin less than $3.5 \mathrm{mg} / \mathrm{dl}$ was $24(77.4 \%)$. The mean serum albumin was $2.8 \pm 0.5 \mathrm{mg} / \mathrm{dl}$ in group I patients and $1.7 \pm 0.4 \mathrm{mg} / \mathrm{dl}$ in group II patients. The albumin in ascitic fluid was $1.2 \pm 0.4 \mathrm{mg} / \mathrm{dl}$ in group I patients and $0.9 \pm 0.3 \mathrm{mg} / \mathrm{dl}$ in group II patients. Similarly, serum-ascites albumin gradient was $1.6 \pm 0.5$ in group I and $0.8 \pm 0.2$ in group II. It was evident that mean serum albumin, ascetic albumin as well as serumascites albumin gradient was significantly higher among the group I patients compared to group II patients $(\mathrm{p}<0.001)$.
\end{abstract}

Keywords: Paediatric, Albumin, Nephrotic, Biochemical 


\section{Introduction}

Chronic liver disease is not uncommon among pediatric population in Bangladesh [1] found that $4 \%$ of hospital admission into pediatric gastroenterology and general pediatric in patient department of a tertiary hospital were due to liver disease and of these $40 \%$ were chronic liver disease. Liver disease persisting for many months without progressive improvement back to normal liver is called chronic liver disease. [2] In broad sense it includes chronic hepatitis and cirrhosis of liver. Portal hypertension is a common complication of chronic liver disease. The gold standard for diagnosis of portal hypertension is direct measurement of portal pressure of hepatic venous pressure gradient. i.e. the difference between wedged hepatic vein pressure and free hepatic venous pressure.[3] These measurements can be obtained only by invasive methods. Which are not feasible in most context of the world. The indirect way to assess portal hypertension is by detection of esophageal varices. A number of potential modalities exist to assess the grades of oesophageal varices including barium radiography, ultrasonography and upper gastro intestinal endoscopy. The upper gastrointestinal endoscopy to diagnose presence of esophageal varices and hence portal hypertension. Barium studies can detect large varices but are unable to give additional clinically important information that may be obtained from either ultrasonography or upper gastrointestinal endoscopy. The noninvasive nature may be limited by the expertise of the sonographer.[4] The serum ascitic fluid albumin gradient (SAAG) the difference between serum albumin and ascitic fluid albumin, has been proved in multiple studies to categorize ascitis better than the total ascitic fluid protein concentration. [5, 6, 7, 8] It has been observed in the literatures devoted to internal medicine that serum ascitic fluid albumin concentration gradient (SAAG) correlates directly with portal pressure. [5, 8] SAAG is calculated by subtracting ascitic fluid albumin concentration from serum albumin concentration. It is a subtraction, not a ratio. If the SAAG is greater than $1.1 \mathrm{gm} / \mathrm{dl}$ the patient has portal hypertension with approximately 97 percent accuracy. [5, 6, 8, 9] There are few similar study in paediatric population. The SAAG being independent of serum albumin concentration is based on oncotic hydrostatic balance.[8] It is proportional to the pressure gradient from portal vein to the intra-abdominal cavity. Portal hypertension results in an abnormally high hydrostatic pressure gradient between the portal bed and acetic fluid. There must be a similar large difference between ascitic fluid and intravascular oncotic forces. [8] Albumin exerts more oncotic force per gram than other protein. So the difference between serum and ascetic fluid albumin concentrations correlates directly with portal pressure [8] The SAAG appears to detain its predictive value despite diuresis, infusion of albumin, therapeutic paracentesis or infection in the ascitic fluid. [10,11] The present study was undertaken to see the SAAG as a predictor of portal hypertension in chronic liver disease in paediatric population. It is the major cause of death in portal hypertension. It can be diagnosed by upper gastro intestinal endoscopy. But endoscopy in paediatric population is not available in our country. It is performed in few centers only. So we need a screening test for portal hypertension before doing upper gastrointestinal endoscopy and the screening test should be simple, practicable, quick, valuable, valid and cost effective. Serum ascitic fluid albumin gradient is cheap and simple test. It can be done easily even in the different district levels in our country. So we can use serum ascitic fluid albumin gradient as a screening test for portal hypertension in ascitic patients.

\section{Objectives}

General objective:

1. To determine the serum ascitic fluid albumin concentration gradient in children with chronic liver disease and nephrotic syndrome

Specific Objective:

1. To evaluated the significance of high SAAG Value (1.1 $\mathrm{gm} / \mathrm{dl}$ ) as a predictor of portal hypertension and low SAAG Value as a predictor of absence of portal hypertension.

\section{Methodology and Materials}

This cross sectional analytic study was conducted in the department of pediatrics, Bangabandu Sheikh Mujib Medical University, Dhaka Medical College Hospital and Dhaka Shishu Hospital for a period of one year and six months. A total of 55 patients were studied. Among them, 31 were chronic liver disease patients with ascites and rest 24 patients were nephrotic syndrome patients with ascites. The mean age of the children was $8.3 \pm 3.6$ years. In the study $81 \%$ of the patients with chronic liver disease were found to have high SAAG $(\geq 1.1 \mathrm{gm} / \mathrm{dl})$ and $100 \%$ of the nephrotic syndrome patients were found to have low SAAG $(<1.1 \mathrm{gm} / \mathrm{dl})$. Mean SAAG value of patients with chronic liver disease was significantly higher than that of nephrotic syndrome patients. Data analysis performed by SPSS 22 version.

Inclusion Criteria

1. Age - 1 Year to 15 years.

2. Sex - Both sex.

3. Sample - Accordingly to group criteria.

Exclusion Criteria

1. Age $<1$ year $>15$ years.

2. Hemodynamic instability: Severe bleeding manifestation Hepatic come.

3. Medical contra indication to perform endoscopy.

4. Acute infection: Spontaneous bacterial peritonitis.

\section{Results}

A total number of 55 children were studied. Among them, 31 children with chronic liver disease with ascites were designated as Group I and rest 24 nephrotic syndrome children with ascites were designated as group II. The mean 
age of the children was $8.3 \pm 3.6$ years ranging from 1.0-15.0 years. The mean age of the male patient was $8.0 \pm 3.6$ years and that of female patients was $9.3 \pm 3.5$ years. No statistically significant mean age difference was found between male and female patients $(p>0.05)$, although female patients had a bit higher mean age than male patients (Table 1). The mean age of the group I patients was 9.2 \pm 3.7 years ranging from 1.014.0 years and group II patients was $7.2 \pm 3.2$ ranging from 2.0 to 15.0 years and the mean age difference between two groups patients was statistically significant $(p<0.05)$ indicated that patients with chronic liver disease had higher age than patients with nephrotic syndrome (Table 2). The clinical presentation of the studied patients revealed that cent percentage of patients had ascites followed by jaundice $(64.5 \%)$, edema $(51.6 \%)$ and gastrointestinal bleeding $(41.9 \%)$. Regarding the presenting signs, splenomegaly (96.8\%), hepatomegaly $77.4 \%$ and palmer erythema $(9.7 \%)$. No patients had spider angioma (Table 3). Out of 31 patients, highest percentage of patients were diagnosed as cirrhosis of liver $(48.4 \%)$. The other types were chronic active hepatitis (6.5\%) and unclassified chronic liver diseases (45.2\%). Chronic liver diseases patients where liver biopsy could not be performed to ascertain the exact nature of the disease were labeled as unclassified chronic liver disease (Figure 1). (Figure 2) shows the aetiology of chronic liver diseases of the group I patients. Out of 31 patients, highest percentage of patients were of unknown etiology 17 (54.9\%) followed by hepatitis B virus 7 (22.6\%) and Wilson's disease 5 (16.1\%). (Table 4) shows the biochemical parameters of the chronic liver disease patients. It was evident that 24 (77.4\%) had serum bilirubin $>1.2 \mathrm{mg} / \mathrm{dl}$, serum ALT $>40$ IU/L was 25 $(80.6 \%)$, prothrombin time more than 3 second than control $23(74.2 \%)$ and serum albumin less than $3.5 \mathrm{mg} / \mathrm{dl}$ was 24 (77.4\%). The mean serum albumin was $2.8 \pm 0.5 \mathrm{mg} / \mathrm{dl}$ in group I patients and $1.7 \pm 0.4 \mathrm{mg} / \mathrm{dl}$ in group II patients. The albumin in ascetic fluid was $1.2 \pm 0.4 \mathrm{mg} / \mathrm{dl}$ in group I patients and $0.9 \pm 0.3 \mathrm{mg} / \mathrm{dl}$ in group II patients. Similarly, serumascites albumin gradient was $1.6 \pm 0.5$ in group I and $0.8 \pm 0.2$ in group II. It was evident that mean serum albumin, ascetic albumin as well as serum-ascites albumin gradient was significantly higher among the group I patients compared to group II patients $(p<0.001)$ (Table 5). (Figure 3 ) shows the correlation of serum albumin with albumin in ascitic fluid and serum albumin with SAAG. Analysis revealed significant positive correlation between serum albumin with albumin in ascitic fluid $(p<0.001)$. Similarly, positive correlation was also found between serum albumin with SAAG $(p<0.001)$. (Table 6 and Figure 4) shows the distribution of oesophageal varices among the low and high SAAG patients. It was observed that among the low SAAG patients, only one (16.7\%) had esophageal varices and $5(83.3 \%)$ had none, whereas among the high SAAG patients, $19(76.0 \%)$ had esophageal varices i.e. $8(32.0 \%)$ grade I, $7(28.0 \%)$ grade II and $4(16.0 \%)$ grade III esophageal varices and $6(24.0 \%)$ had no varices and the difference was statistically significant $(p<0.05)$ indicated that esophageal varices were associated with high SAAG. (Figure 5) shows the relationship of oesophaseal varices with serum ascites albumin gradient. Analysis revealed that a significant positive correlation was found between the serum ascites albumin gradient and esophageal varices $(p<0.05)$ and also indicated that increased SAAG increased the number and grades of oesophaseal varices. Analysis revealed that among the patients with low SAAG, no patients had history of G. I bleeding, whereas patients with high SAAG $(\geq 1.1 \mathrm{~g} / \mathrm{dl}), 13(52.0 \%)$ had history of G. I bleeding and $12(48.0 \%)$ had no history of bleeding. This indicated that high SAAG $(\geq 1.1 \mathrm{~g} / \mathrm{dl})$ was significantly associated with gastrointestinal bleeding $(p<0.02)$ (Table 7$)$.

Table 1. Age and Sex Distribution of the Study Subjects $(n=55)$.

\begin{tabular}{lllll}
\hline \multirow{2}{*}{ Age in year's } & Sex & & \multirow{2}{*}{ Total (\%) } & \multirow{2}{*}{ p value } \\
\cline { 2 - 3 } & Male (\%) & Female (\%) & & \\
\hline$<5$ & $9(20.9)$ & $1(8.3)$ & $10(18.2)$ & \\
$5-9$ & $17(39.5)$ & $4(33.3)$ & $21(38.2)$ & \multirow{2}{*}{0.266} \\
$\geq 10$ & $17(39.5)$ & $7(58.3)$ & $24(43.6)$ & \\
Total & $43(78.2)$ & $12(21.8)$ & $55(100.0)$ & \\
\hline
\end{tabular}

$\mathrm{p}$ value reached from unpaired student's t test $(p>0.05)$

Table 2. Age Distribution of the Study Subjects ( $n=55)$.

\begin{tabular}{lllll}
\hline \multirow{2}{*}{$\begin{array}{l}\text { Age in } \\
\text { years }\end{array}$} & \multicolumn{2}{l}{ Study subjects } & \multirow{2}{*}{ Total (\%) } & \multirow{2}{*}{ p value } \\
\cline { 2 - 3 } & Group I (\%) & Group II (\%) & & \\
\hline$<5$ & $4(12.9)$ & $6(25.0)$ & $10(18.2)$ & \\
$5-9$ & $9(29.0)$ & $12(50.0)$ & $21(38.2)$ & \multirow{2}{*}{$0.036^{*}$} \\
$\geq 10$ & $18(58.1)$ & $6(25.0)$ & $24(43.6)$ & \\
Total & $31(56.4)$ & $24(43.6)$ & $55(100.0)$ & \\
\hline
\end{tabular}

Group I=Patients with chronic liver disease, Group II=patients with nephritic syndrome, $\mathrm{p}$ value reached from unpaired student's t test $*(p<0.05)$

Table 3. Distribution of Patients by Clinical Presentation of Chronic Liver Diseases $(n=31)$.

\begin{tabular}{lll}
\hline Clinical Presentation & Number & \% \\
\hline Symptoms & 31 & 100 \\
Ascites & 20 & 64.5 \\
Jaundice & 16 & 51.6 \\
Edema & 13 & 41.9 \\
G. I bleeding & & \\
Signs & 30 & 96.8 \\
Splenomegaly & 24 & 77.4 \\
Hepatomegaly & 3 & 9.7 \\
Palmer erythema & 0 & 0.0 \\
Spider angioma & & \\
\hline
\end{tabular}

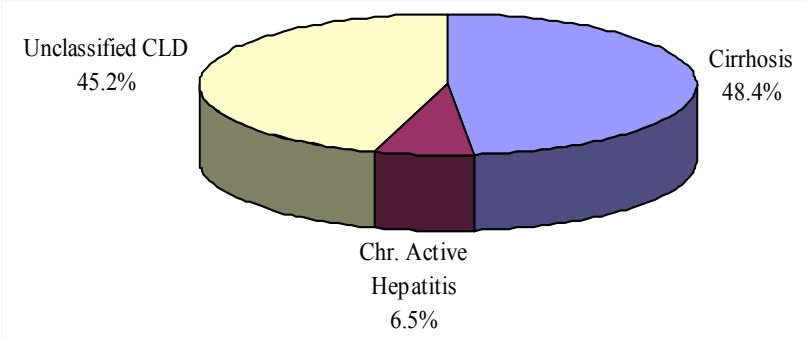

Figure 1. Pie Diagram Showing the Types of Chronic Liver Diseases. 


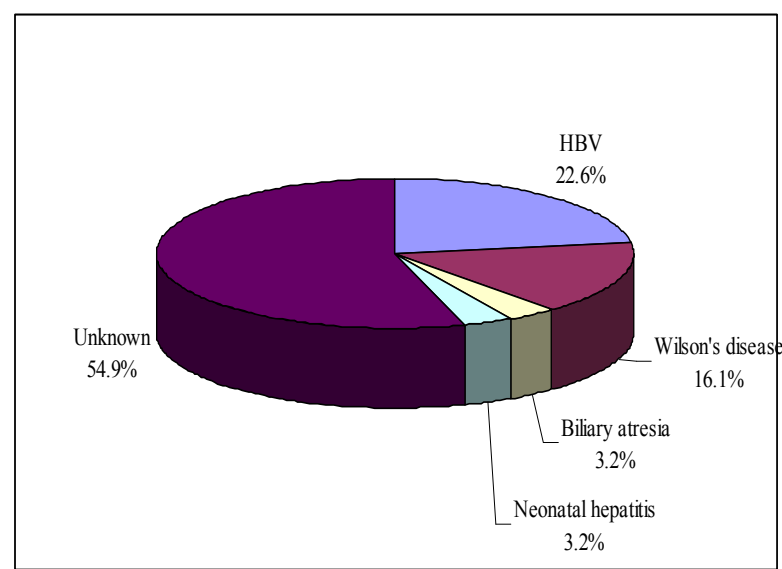

Figure 2. Pie Diagram showing the etiology of Chronic Liver Diseases $(n=31)$.

Table 4. Biochemical Parameters of Chronic Liver Diseases ( $n=31)$.

\begin{tabular}{lll}
\hline Parameters & Number & \% \\
\hline Serum Bilirubin & & \\
$<1.2 \mathrm{mg} / \mathrm{dl}$ & 7 & 22.6 \\
$>1.2 \mathrm{mg} / \mathrm{dl}$ & 24 & 77.4 \\
ALT & & \\
\hline
\end{tabular}

\begin{tabular}{lll}
\hline Parameters & Number & \% \\
\hline$<40 \mathrm{IU} / \mathrm{L}$ & 6 & 19.4 \\
$>40 \mathrm{IU} / \mathrm{L}$ & 25 & 80.6 \\
Prothrombin time & & \\
$<3$ second than control & 8 & 25.8 \\
$>3$ second than control & 23 & 74.2 \\
Serum albumin & & \\
$<3.5 \mathrm{mg} / \mathrm{dl}$ & 7 & 22.6 \\
$>3.5 \mathrm{mg} / \mathrm{dl}$ & 24 & 77.4 \\
\hline
\end{tabular}

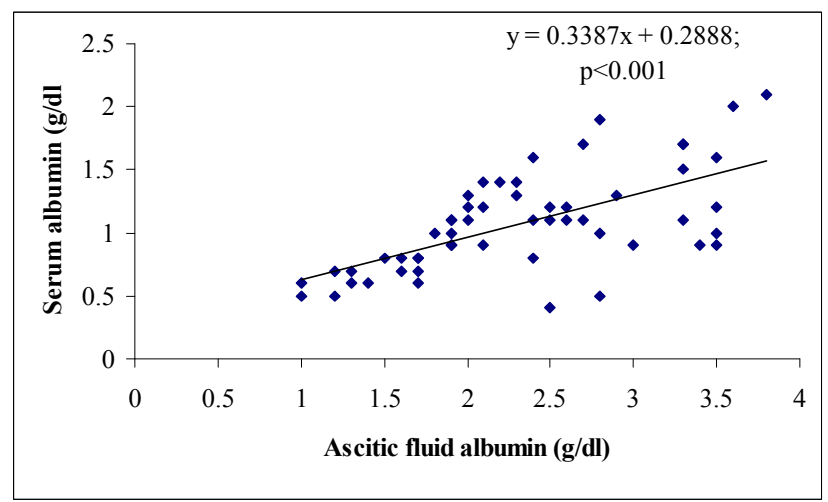

Figure 3. Correlation of Serum Albumin with Albumin in Ascitic Fluid.

Table 5. Mean Distribution of Albumin level in Serum and Ascitic Fluid in the Study Subjects ( $n=55$ ).

\begin{tabular}{llll}
\hline Variable & Group I & Group II & p value \\
\hline Serum albumin (mg/dl) (Range) & $2.82 \pm 0.5(1.7-3.8)$ & $1.7 \pm 0.4(1.0-2.3)$ & $0.001^{* * *}$ \\
Albumin in Ascitic fluid (mg/dl) (Range) & $1.2 \pm 0.4(0.4-2.1)$ & $0.9 \pm 0.3(0.5-1.4)$ & $0.002^{* *}$ \\
Serum-ascitic albumin gradient (Range) & $1.6 \pm 0.5(0.7-2.6)$ & $0.8 \pm 0.2(0.4-1.0)$ & $0.001^{* * *}$ \\
\hline
\end{tabular}

Group I=Patients with chronic liver disease,

Group II=patients with nephrotic syndrome, p value reached from unpaired student's t test ${ }^{* *} p<0.01$; ${ }^{* * *} p<0.001$;

Table 6. Distribution of Oesophageal Varies of the Group I Subjects ( $n=31$ ).

\begin{tabular}{|c|c|c|c|c|}
\hline \multirow{2}{*}{ Oesophageal varices } & \multicolumn{2}{|l|}{ Serum-ascites albumin gradient } & \multirow{2}{*}{ Total (\%) } & \multirow{2}{*}{ p value } \\
\hline & Low SAAG $(<1.1 \mathrm{gm} / \mathrm{dl})(\%)$ & High SAAG $(\geq 1.1 \mathrm{gm} / \mathrm{dl})(\%)$ & & \\
\hline Absent & $5(83.3)$ & $6(24.0)$ & $11(35.5)$ & $0.024 *$ \\
\hline Grade I & $0(0.0)$ & $8(32.0)$ & $8(25.8)$ & \\
\hline Grade II & $1(16.7)$ & $7(28.0)$ & $8(25.8)$ & \\
\hline Grade III & $0(0.0)$ & $4(16.0)$ & $4(12.9)$ & \\
\hline Total & $6(19.4)$ & $25(80.6)$ & $31(100.0)$ & \\
\hline
\end{tabular}

$\mathrm{p}$ value reached from chi square test with Yates correction ${ }^{*} p<0.05$

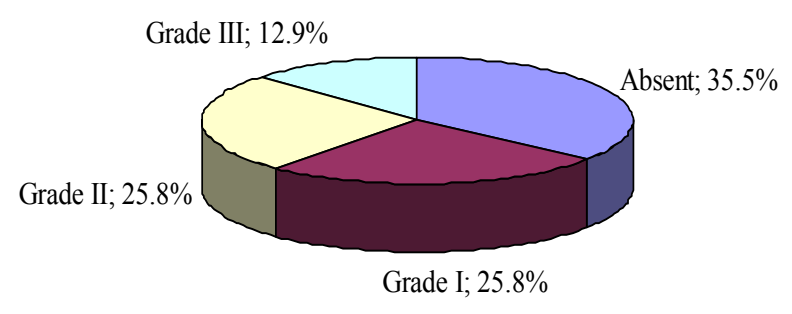

Figure 4. Pie Diagram Showing the Oesophageal Varies among the Group I Subjects.

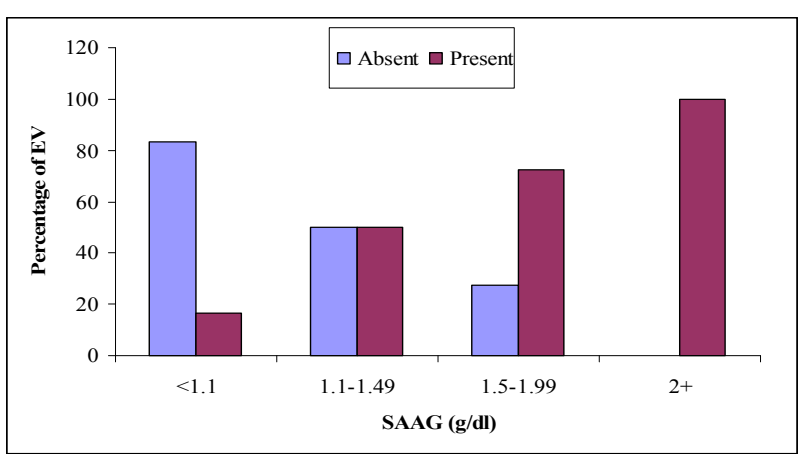

Figure 5. Relationship of Serum Ascites-Albumin Gradient and Oesophageal Varices in group I patients. 
Table 7. Relationship of Gastrointestinal Bleeding and Serum-Ascites Albumin Gradient among Group I Subjects (n=31).

\begin{tabular}{|c|c|c|c|c|}
\hline \multirow{2}{*}{ G. I bleeding } & \multicolumn{2}{|l|}{ Serum-ascites albumin gradient } & \multirow{2}{*}{ Total (\%) } & \multirow{2}{*}{ p value } \\
\hline & Low SAAG $(<1.1$ gm/dl) $(\%)$ & High SAAG ( $\geq 1.1 \mathrm{gm} / \mathrm{dl})(\%)$ & & \\
\hline Yes & $0(0.0)$ & $13(52.0)$ & $13(41.9)$ & 0.028* \\
\hline No & $6(100.0)$ & $12(48.0)$ & $18(58.1)$ & \\
\hline Total & $6(19.4)$ & $25(80.6)$ & $31(100.0)$ & \\
\hline
\end{tabular}

$\mathrm{p}$ value reached from fisher exact test $* p<0.05$.

\section{Discussion}

In this present study, oesophageal varices were found in only $17 \%$ of chronic liver disease patients with low SAAG. It is consistent with the finding of the study [13] but differ from the study [14] who got slightly higher percentage of patients with oesophageal varices. This difference is possibly due to small sample size of the later author. So in case of low SAAG, there is less chance of presence of oesophageal varices and therefore endoscopy can be delayed. Of course, both groups of chronic liver disease patients with ascites should be transferred to a tertiary care facility, but having a SAAG values may help in terms of to take decision of doing endoscopy. In this study the SAAG strongly differentiated chronic liver disease patients with oesophageal varices from those without oesophageal varices. In the study sensitivity of predicting oesophageal varices $(76 \%)$ was reasonable and specificity $(83 \%)$ was good with a high positive predictive value $(95 \%)$. These results are similar to earlier studies but predictive accuracy (77\%) was slightly lower than that of previous studies. [14, 15] These differences may be due to small sample size of the present study and difference in study population. Cirrhosis of liver, portal vein obstruction, congenital hepatic fibrosis and hepatic vein outflow obstructions are the main causes of portal hypertension in children. In present study, the majority of subjects had cirrhosis of unknown etiology. Positive correlation was found between the SAAG and serum albumin but no correlation with serum bilirubin and prothrombin time. This finding consistent with the finding of [16]. Severity of liver dysfunction can alter the intravascular resistance and hence, degree of portal hypertension and upper gastro intestinal bleeding. Therefore, further studies including large number of patients should be performed to answer the above question. The presence of a high albumin gradient does not diagnose cirrhosis; It simply indicates the presence of portal hypertension. The albumin gradient need only to be performed on the first paracentesis in a given patient. It need not be repeated in subsequent specimens if the first value is definitive. If the albumin assay is not accurate at low range, errors will occur. Also, if a cirrhotic patient has a low serum albumin level of less than $1.1 \mathrm{gm} / \mathrm{dl}$ (this occurs in less than 1 percent of cirrhotic ascites patients), the gradient will be falsely low. There are other situations in which accuracy decreases, such as when specimens are not obtained relatively simultaneously. The specimens should be obtained on the same day preferably within the same hour. Both serum and ascitic fluid albumin concentrations change over time; however, these values change in parallel such that the difference is stable. Peripheral hypotension may result in a decrease in the portal pressure and a narrowing of the albumin gradient. Lipid interferes with the albumin assay such that chylous ascites may have a falsely high albumin gradient. Hyperglobulinemia ( $>5 \mathrm{gm} / \mathrm{dl}$ ) leads to a high ascitic fluid globulin concentration and can narrow the albumin gradient by contributing to the oncotic forces. A narrow gradient due to high globulin occurs in only approximately I percent of ascitic fluid specimens. To correct the SAAG in the setting of a high serum globulin level, the uncorrected SAAG is multiplied by $(0.21+0.208 \times$ Serum globulin $)$. From the above discussion, taking into account the correlation between SAAG and PP- GRAD, the simple and minimally invasive technique of measuring SAAG may prove useful as an indirect indicator of estimating portal hypertension and its associations such as oesophageal varies. A SAAG value of $\geq 1.1 \mathrm{gm} / \mathrm{dl}$ is a useful means to predict the presence of portal hypertension and hence oesophageal varices in children with ascites.

\section{LIMITATIONS OF THE STUDY}

The study was conducted in three hospitals. This along with time limitation and the children being severely sick and with medical emergency \& complication led to inclusion or each and every consecutive admitted case in the study population difficult.

\section{Conclusion}

From the present study it may be concluded that the difference between serum albumin and ascitic fluid albumin concentration correlates directly with portal pressure and a high SAAG value indicates portal hypertension. High SAAG denotes higher chances of presence of oesophageal varices in children with ascites due to chronic liver disease. SAAG value of $\geq 1.1 \mathrm{gm} / \mathrm{dl}$ is a useful indicator to predict the oesophageal varices in children with ascites and can guide the paediatricians to determine the urgency of care. Another aspect of studying the SAAG value to detect the grades of oesophageal varices is important. Because grading of oesophageal varices has prognostic value. Grades of oesophageal varices and upper gastrointestinal bleeding have a positive correlation with the high SAAG value.

\section{Funding Source}

Self. 


\section{Conflict of Interest}

Not declared.

\section{Approval}

From respective department.

\section{References}

[1] Karim, A. S. M. B., Akhter, S., Karim, M. A. \& Nazir, M. F. H. 1999, 'A study of the clinical profile of chronic liver diseases in children', DS (Child) HJ, vol. 15. No. 1 \& 2, pp. 16-19.

[2] Lucas. A. \& Elia, M. 1990, 'The chronic liver diseases spectrum', Medicine International, vol. 3, pp. 3460.

[3] Sherlock, S. \& Dooley, J. 2002, 'Hepatic cirrhosis' in Diseases of the Liver and Biliary System, 11th end, Blackwell science, Oxford, pp. 365-380.

[4] Valeta, E. A., Loreti, S., Cipolli, M., Cazzola, G. \& Zanolla, I. 1993, 'Portal hypertension and esophageal varices in cystic fibrosis: unreliability of echo-doppler flowmetry', Scand J. Gastroenterol, vol. 28, pp. 1042-1016.

[5] Runyon, B. A., Montano, A. A., Akriviadis, E. A., Antillon, M. R., Irving, M. A. \& McHutchison, J. G. 1992, 'The serumascites albumin gradient in the differential diagnosis of ascites is superior to the exudate-transudate concept', Ann Intern Med, vol. 117 , pp. 215-220.

[6] Rector, W. G. \& Reynolds, T. B. 1984, 'Superiority of serumascites albumin difference over the ascites total protein concentration in separation of transudative and exudative ascites', Am J Med, vol. 77, pp. 83-85.

[7] Pare, P., Talbot, J. \& Hoefs, J. C. 1983, 'Serum-ascites albumin concentration gradient: a physiologic approach to the differential diagnosis of ascites', Gastroenterology, vol. 85, pp. 240-244.
[8] Hoefs, J. C. 1983, 'Serum protein concentration and portal pressure determine the ascitic fluid protein concentration in patients with chronic liver diseae', Lab Clin Med, vol. 102, no. 2, pp. $260-273$.

[9] Salam, K. M. A. 1989, 'Aetiology of ascites in children', FCPS (Paediatrics) Dissertation, BCPS, Dhaka.

[10] Runyon, B. A. 1993, 'Ascites and spontaneous bacterial peritonitis', in Gastrointestinal Disease: pathophysiology, diagnosis and management, vol. II. 5th edn, eds. M. H. Sleisenger \&, J. S. Fordtran, W. B. Saunders Company, Philadelphia, pp. 1997-2003.

[11] Runyon, B. A. 1994, 'Care of patients with ascites', N Engl J Med, vol. 330, no. 5, pp. 337-342.

[12] Kajani, M. A., Yoo, Y. K., Alexander, J. A., Gavaler, J. S., Stauber, R. E., Dindzans, V. J. et al. 1990, 'Serum-ascites albumin gradients in nonalcoholic liver disease', Dig Dis Sci, vol. 35, no. 1, pp. 33-37.

[13] Torres, E., Barros, P. \& Calmet, F. 1998, 'Correlation between serum- ascites albumin concentration gradient and endoscopic parameters of portal hypertension', Am J Gastroenterol, vol. 93, no. 11 , pp. 2172-2178.

[14] Das, B. B., Purohit., A., Acharya, U. \& Treskova, E. 2001, 'Serum-Ascites Albumin Gradient: predictor of Esophageal Variecs with Ascites', Indian J Pediatr, vol. 68, no. 6, pp. 511514.

[15] Akriviadis, E. A., Kapnias, D., Hadjigavriel, M., Mitsiou, A. \& Goulis, J. 1996, 'Serum/ascites albumin gradient: its value as a rational approach to the differential diagnosis of ascites', Scand J Gastroenterol, vol. 31, no. 8, pp. 814-817.

[16] Torres, E., Calmet, F. \& Barros, P. 1996, 'Endoscopic and clinical parameters in assessing the degree of portal hypertension; the value of serum ascites albumin gradient', Rev Gastroenterol Peru, vol. no 1, pp. 20-26. 